tories, demonstrates the presence of some 0.2 per cent of nickel, with smaller quantities of other elements ( $\mathrm{Si}, \mathrm{Al}, \mathrm{Fe}, \mathrm{Mn}, \mathrm{Mg}, \mathrm{Na}, \mathrm{K}, \mathrm{Ti}, \mathrm{Co}, \mathrm{Cr}$, $\mathrm{Cu}, \mathrm{B})$. This points to a probable explanation of the subsidiary structure. $\beta$-Nickel has a face-centred cubic structure of lattice constant $3.52 \mathrm{~A}$.; nickel carbide, a solid solution $\mathrm{Ni}_{x} \mathrm{C}$ where $x \geqslant 4$, is facecentred cubic above $210^{\circ} \mathrm{C}$. and has ${ }^{1}$ the slightly higher parameter $3 \cdot 54 \mathrm{~A}$. A simple face-centred cubic structure would not account for the high intensity of 200 relative to other lines in the satellite structure. The addition of some impurity or solvent atoms could do so. A calculation shows that for incident nickel, copper $K \alpha$ or molybdenum radiation, even so small an amount of nickel as 0.2 per cent, concentrated in a fow well-crystallized and parallel islands, would give reflexions of appreciable intensity, but that for chromium or copper $K \beta$ radiation they would be much reduced in intensity if the extent of each island is more than some $4 \times 10^{-4} \mathrm{~cm}$. linear. This reduction in intensity is found to occur.

Nickel does not normally appear as an impurity in natural diamonds. The closeness of its lattice constant to that of diamond would point to it, however, as a possible inducer of crystallization of carbon in the diamond form (much as $\beta$ silver iodide can induce the precipitation of ice in clouds). The process of cooling from high temperatures and simultaneously expanding from high pressures could well leave islands of face-centred cubic nickel or $\mathrm{Ni}_{x} \mathrm{C}$ or some other nickel compound in a state of strain; and the existence of orientation relationships (not necessarily complete parallelism) in a precipitated phase is typical, for example, of Widmanstätten patterns in iron-rich nickel-iron alloys in diamond-bearing meteorites. The presence of nickel in these laboratorymade diamonds recalls the Press release (February 15 , 1955) by the Research Laboratory of the General Electric Co., in which it was stated that its scientists had "gained valuable help from nature, particularly from studies of diamonds found in Arizona moteorites". This will be discussed in our later paper.

The question still remains as to the actual mechanism of transformation from graphitic carbon (assuming this to be the initial substance) to diamond. This could in fact occur via an intermediate carbon structure, as shown in Fig. 2. This structure, if it has carbon atoms in the positions $\left(x \sim \frac{1}{24}\right)$

$000,0 \frac{1}{2} \frac{1}{2}, \frac{1}{2}, \frac{1}{2} \frac{1}{2} 0+\left|\vec{x} \bar{x} \bar{x} ; \frac{1}{4}+x, \frac{1}{4}+x, \frac{1}{4}+x\right|$ in a unit cell which is geometrically cubic, of side 3.54 A., but of rhombohedral symmetry only, would give reflexions in precisely the positions of the satellite spots. Apart from the variation of absorption factor with incident radiation, the occurrence of such an intermediate structure, in islands, each with its trigonal axis orientated parallel to one of the four diamond octahedral directions, could scarcely be distinguished from that of the nickel-rich islands we have postulated as the main cause of the satellite reflexions.

Nath $^{2}$ suggested in 1935 that the reverse transformation, diamond $\rightarrow$ graphite, might take place via rhombohedral graphite, but no experimental evidence of this has yet been found, even in heavily irradiated or heat-treated diamonds ${ }^{3}$. We should also emphasize that even the blackest of the laboratory-made diamonds examined showed no trace whatever of the strong 0002 reflexion typical of both hexagonal and rhombohedral graphites, or any other purely graphitic reflexion.
We would like to express our thanks to members of the research staff of the General Electric Company, Schenectady, who, within the limitations of United States security regulations, have given us every assistance in this investigation.

$$
\begin{aligned}
& \text { H. Judirh Grenville-Wells } \\
& \text { KathleEN Lonsdale }
\end{aligned}
$$

University College,

London, W.C.1.

${ }^{1}$ Bernier, R., Ann. Chim., 6, 104 (1951); distances given here as in $A$. are really in $\mathrm{kX}$., and must be multiplied by 1.00202 . 2 Nath, N. S. N., Proc. Ind. Acad. Sci., A, 1, 841 (1935).

${ }^{3}$ Grenville-Wells, H. J., Thesis, London (1951).

\section{Nuclear Quadrupole Resonance of Neutron-irradiated Sodium Chlorate}

RECENTLY a method based on intensity measurements in pure quadrupole resonance has been developed and has proved itself useful for the study of solid solutions ${ }^{1}$ and for the investigation of the damage induced in pure solid compounds by highenergy radiations such as gamma-rays ${ }^{2}$.

The present work was undertaken in order to try to extend this method to the case of neutrons. With this in view, fused samples of sodium chlorate, which presents a favourable signal-to-noise ratio, were irradiated at $95^{\circ} \mathrm{C}$. in the Belgian $B R-1$ reactor in which a high ratio of neutron to gamma energy is provided. A frequency-modulated super-regenerative detector was used and the spectra were automatically recorded after phase-sensitive detection of the signals.

The observations performed at $23^{\circ} \mathrm{C}$. showed that the height of the line (located at 29.932 Mc./sec.) corresponding to chlorine-35 was decreased by about 25,36 and 52 per cent for irradiations with doses of $2 \times 10^{14}, 10^{15}$ and $2 \times 10^{15}$ fast neutrons cm. ${ }^{-2}$, respectively. We were unable to detect any signifi. cant shift in the line frequency and, as was found to occur with the gamma-rays ${ }^{2}$, a plot of $\log I$ (irradiated sample) - $\log I_{0}$ (unirradiated sample) versus the dose gave a straight line. This shows that, despite a different type of effect, an exponential law still describes the intensity behaviour. It should be noticed that, within the range of doses used, no significant broadening of the line (measured by the separation between the peaks of the first derivative curve) was observed. For this reason, the intensity of the line was regarded as being satisfactorily represented by its height.

It may now be stated that the method here reported is also valuable for the study of damage induced by neutrons. Further research, including radio-resistance in terms of structure and recovery effects, is now in progress.

We are indebted to the Centre d'Etudes pour les applications de l'Energie Nucléaire for irradiation facilities.

\section{JOSEPH DEPIREUX} Jules DUChesne

Institut d'Astrophysique, University of Liège. Jan. 10.

${ }^{1}$ Duchesne, J., and Monfils, A., C.R. Acad. Sci., Paris, 238, 1801 (1954). Dean, C., J. Chem. Phys., 23, 1734 (1955). Segel, S. L. and Lutz, B. C., Phys. Rev., 98. 1183 (1955). Monfle, A., and Grosjean,D., Physica, 22, 541 (1956). Michel, R. E., and Spence, R. D., J. Chem, Phys. 26, 954 (1956). Dreyfus, B., and Dautreppe D., C.R. Acad. Sci., Paris, 243,1517 (1956). Woessner, D. E., and Gutowsky, H. S., J. Chem. Phys., 27, 1072 (1957).

2 Duchesne, J., Monfils, A.. and Garsou, J., J. Chem. Phys., 23, 1969 (1955). Mionfils, A., and Duchesne, $\dot{J}$,. P Physica, 22, 818 (1956). Duchesne, J., Monfils, A., and Depireux, J., C.R. Acad. Sci. Paris, 243, 259 (1956). Duchesne, J., Arch. Sci. Geneve, 10, 257 (1957). 